\title{
Behaviour of Streptomycetes in Soil
}

\author{
By A. B. LLOYD* \\ Department of Plant Pathology, Waite Agricultural Research Institute, University \\ of Adelaide, South Australia
}

(Accepted for publication 7 January 1969)

SUMMARY

\begin{abstract}
Most of the conidia from eight different streptomycetes did not germinate in natural soil under conditions apparently suitable for their germination. When germinated in nutrient solution and then added to soil, they grew for a limited period, sporulated and then the vegetative hyphae disappeared, leaving behind only spores.

Streptomycete conidia produced naturally in garden soil decreased in number by about a half after I 2 days. Nevertheless, the conidia are the main means of survival and it appears that streptomycetes exist in soil mainly as spores. Mycelia also existed, but in the main were restricted to micro-sites where nutrient was available.
\end{abstract}

\section{INTRODUCTION}

Streptomycetes are widely distributed in soils, especially in those which are dry and not too acid, and those rich in organic matter; here, in propagule numbers, they frequently exceed the combined counts of all other bacteria (Alexander, I96I; Waksman, 1959). They decompose plant and animal residues, for the addition of these residues to soil greatly increases the activity and size of the streptomycete population (Alexander, 1961; Waksman, 1959).

It is still debatable whether streptomycetes occur in soils mainly as vegetative mycelia or as spores (Waksman, 1959). Lutman, Livingston \& Schmidt (1936) concluded from soil smears and from heating soil to kill vegetative mycelia that streptomycetes occur mainly as mycelia. On the other hand, Subrahmanyan (I929), from observations on the origin of colonies arising on dilution plates, and Pfennig (1958), from glass slides buried in soil, concluded that they exist mainly as spores; mycelium was restricted to colonization of plant and animal residues but was found in the soil itself.

Skinner (1951) attempted to solve the problem of how streptomycetes exist in soil by shaking soil samples with sand particles, reasoning that this would increase the propagule numbers by breaking the mycelium into many viable fragments if the streptomycetes were present mainly as mycelium. However, no increase in propagule numbers occurred, and Skinner therefore concluded that the streptomycetes were present, and presumably persisted in soil, as spores rather than as mycelium.

In this paper I have attempted to answer the same question, but by using a more direct method than that employed by Skinner.

* Present address: Department of Agricultural Biology, University of New England, Armidale, N.S.W., Australia 235 I. 


\section{METHODS}

Soil. The soil used (Urrbrae loam) was a red-brown earth with a silty loam texture and a pronounced fine sand fraction (Piper, 1938). Red-brown earths occur throughout the wheat-growing areas of South Australia as well as in other parts of Australia. Soil was collected from three sites, all within the grounds of the Waite Agricultural Research Institute: (I) a field in pasture for the previous five years (pasture soil); (2) an experimental plot sown continuously with wheat without nitrogen fertilizer since 1929 (wheat-field soil); (3) an ornamental flower garden with a dark-coloured soil of high organic content (garden soil).

Soil samples collected from these sites were passed through a sieve ( $2 \mathrm{~mm}$. mesh) and then stored for a short period in plastic bags at room temperature. The approximate numbers of streptomycete propagules/g. dry weight of the stored soils ranged from $9.2 \times 10^{5}$ to $3.3 \times 10^{6}$, based on counts made from dilution plates with chitin agar (Lingappa \& Lockwood, 1962; Lloyd, Noveroske \& Lockwood, 1965).

When required, garden and wheat-field soils were sterilized by $\gamma$-irradiation, the exposure dosage being $5 \mathrm{Mrad}$. from a ${ }^{60} \mathrm{Co}$ source.

Streptomyces species. Isolates of Streptomyces spp. were obtained from garden soil by spraying a diluted soil suspension over the surface of chitin agar (Lingappa \& Lockwood, 1962), and subsequently transferring single colonies to agar slopes. From these isolates a few were selected which obviously differed from one another in appearance and in the morphology of their sporophores (Pridham, Hesseltine \& Benedict, 1958).

Spore germination, germling (germinated conidia) growth and conidial survival on soil were assayed by a direct method (Lingappa \& Lockwood, r963; Bumbieris \& Lloyd, 1967). In brief, either conidia or germlings from different isolates of Streptomyces spp. were washed thoroughly in I/IO mineral solution (Pridham \& Gottlieb, I948) and then 3 or 4 drops of a conidial or germling suspension spread over the surface of moist soil ( 18 to $20 \%$ soil moisture) in a Petri dish and incubated at $27^{\circ}$. At different time intervals the streptomycetes were stained on the soil surface with $I \%$ rose bengal and then recovered in a plastic film made from a solution of polystyrene. Conidia or germlings recovered from soil immediately after deposition served as controls (Pl. I, fig. I).

\section{RESULTS}

Disappearance of hyphae in soil. The germlings (Pl. I, fig. I) of eight different Streptomyces isolates added to unsterilized garden soil grew into hyphae during the first I to 2 days, sporulated abundantly by the third day, and then most vegetative hyphae disappeared. Occasionally a germtube failed to grow and instead fragmented into rectangular arthrospores whose linear pattern preserved the general shape of the original germling. Thus in unsterilized garden soil by 3 days there existed arthrospores, sporophores (Pl. I, fig. 2), abundant conidial chains and individual scattered conidia (Pl. I, fig. 3), and an increased bacterial population, but few or no vegetative hyphae in the region of soil once occupied by the germlings. The sequence was similar in unsterilized wheat-field soil, except that the process was slower with fewer conidia formed.

With sterilized soils the picture was different. Both sterilized garden and wheat-field 
soils supported abundant vegetative growth of mycelia (Pl. I, fig. 4), and sporulation was so dense that spores were visible in mass on the soil surface.

Inhibition of spore germination by soil. Germinated conidia, when added to unsterilized soil, grew for a short period, sporulated and then the hyphae disappeared, leaving mainly conidia behind in the soil. Now, if these conidia are the survival propagules of streptomycetes, then, presumably, they do not all germinate spontaneously in soil. This hypothesis was next tested.

Table I. Germination of streptomycete spores on natural soils, irradiation-sterilized soil and water agar

\begin{tabular}{|c|c|c|c|c|c|}
\hline \multirow[b]{2}{*}{$\begin{array}{c}\text { Strepto- } \\
\text { mycete } \\
\text { isolate }\end{array}$} & \multicolumn{5}{|c|}{ Percentage spore germination* } \\
\hline & $\begin{array}{c}\text { Garden } \\
\text { soil }\end{array}$ & $\begin{array}{c}\text { Pasture } \\
\text { soil }\end{array}$ & $\begin{array}{l}\text { Wheat- } \\
\text { field } \\
\text { soil }\end{array}$ & $\begin{array}{l}\text { Sterilized } \\
\text { soil }\end{array}$ & $\begin{array}{c}\text { Water } \\
\text { agar }\end{array}$ \\
\hline 100 & I & 13 & 4 & 77 & 94 \\
\hline 102 & 3 & 7 & I I & 75 & 95 \\
\hline 105 & 5 & 9 & 7 & 66 & 94 \\
\hline I I I & 7 & 4 & II & 65 & 76 \\
\hline I 12 & 2 & 2 & 3 & - & - \\
\hline I 13 & 2 & 14 & 2 & 87 & 77 \\
\hline 117 & 2 & 4 & 2 & 9 I & $9 \mathrm{I}$ \\
\hline 118 & I & 6 & 2 & 90 & 96 \\
\hline Average & 3 & 7 & 5 & 79 & 89 \\
\hline
\end{tabular}

Washed conidia of eight different Streptomyces isolates were added to unsterilized soils and incubated for 2 days: most failed to germinate (Table 1 ). The range of germination was $\mathrm{I}$ to $7 \%$ on garden soil, 2 to $14 \%$ on pasture soil and 2 to $1 \mathrm{I} \%$ on wheat-field soil. Most isolates behaved similarly with lower germination on garden soil than on pasture or wheat-field soil. That inhibition of spore germination was closely associated with the presence of other soil micro-organisms was shown by the high germination rate $(65$ to $90 \%$ ) on both garden soil and pasture soil previously sterilized by $\gamma$-irradiation (Table I). Nevertheless, a few conidia from each Streptomyces isolate did germinate on natural soils (Table I). In most cases the emergent germtube quickly produced a terminal sporophore which subsequently sporulated. In other cases the germtube failed to develop further, and fragmented into arthrospores. Occasionally, when conidia were put on the soil in clumps, several spores germinated from within the same clump (Pl. I, fig. 5).

Survival of conidia in soil. Two separate methods were used: (a) germlings of four different Streptomyces isolates were added to garden soil and incubated for 3 days. During that time they grew and sporulated, leaving behind localized regions of high conidial density (soil-grown conidia). From within these regions, five separate areas (each $600 \mu^{2}$ ) were selected, and the conidia counted. Although this non-random sampling was undesirable, it was necessary because the regions of high conidial density were separated from each other by soil almost devoid of conidia. (b) With the second method, culture-grown conidia were added to garden soil and then random areas of soil were examined immediately and at different time intervals.

With soil-grown conidia (Fig. I $a$ ) the conidial population of 3 of the 4 isolates 
decreased rapidly during the first week, but thereafter the mortality rate declined. The fourth isolate was irregular. By the end of 12 days in soil, the combined conidial populations from all 4 isolates had decreased to about half the original number. Culture-grown conidia behaved similarly except that the mortality rate was accelerated after I 2 days with 3 of the 4 isolates (Fig. I $b$ ). By I 6 days the combined populations had decreased to about one-third the original number. Streptomyces isolate 100 was unique: the conidial population added to soil was small, and this decreased during the first week but thereafter remained relatively stable. Perhaps in this case so few alien spores were added to the soil that their presence disturbed the rest of the soil's natural microflora very little. Hence these few introduced spores encountered less antagonism from the soil's natural microflora than occurred when large numbers of alien spores were added to soil, as was the case with the other 3 isolates.
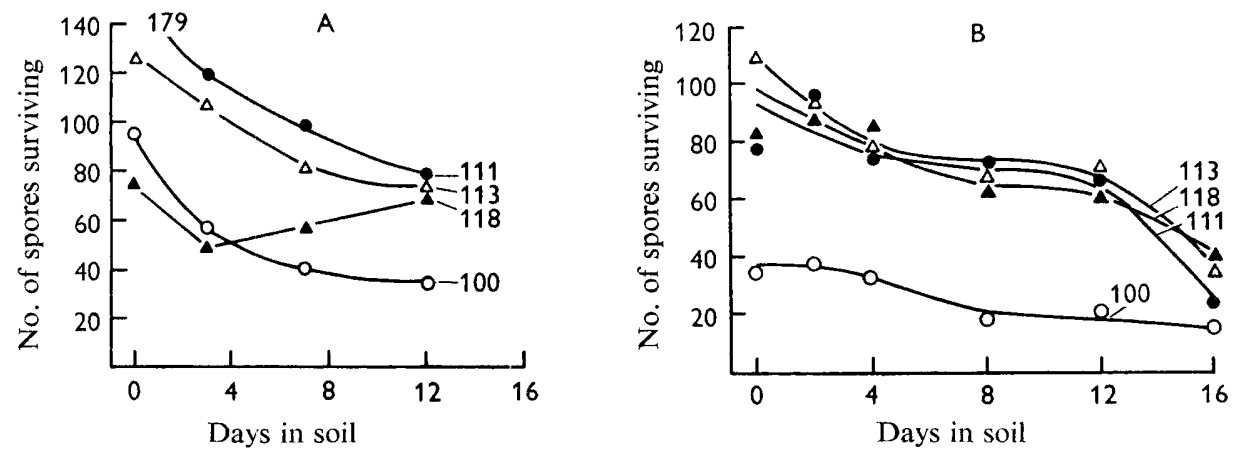

Fig. I. Survival in soil of conidia from four different Streptomyces isolates.

(a) Germinated conidia were added to garden soil, where they grew and sporulated within 3 days. At the end of the 3 days counts were made of the conidia present (o days), followed by counts every fourth day thereafter. (b) Culture-grown conidia of the same Streptomyces isolates were added directly to soil and conidial counts were made immediately (o days) and every fourth day thereafter.

The decline in conidial numbers with time may not be as great as suggested here, for the population is dynamic; some spores are destroyed while a few others germinate, grow and sporulate to partly replenish the declining spore population. In this study I counted only those conidia which were originally present at o days and ignored any spores formed during the time of the experiment. These newly formed spores could be recognized because they were either attached to sporophores or in chains.

After 16 days drops of $0 \cdot 1 \%$ peptone solution were added to soil containing the culture-grown spores, and the following day the number of spores which germinated was counted. Results were as follows: isolate I00, $63 \%$; isolate III, 70\%; isolate II 3 , $86 \%$; isolate I $8,6 \mathrm{I} \%$. Spores from the same isolates, when similarly tested one day after placement on soil, gave results of $7 \mathrm{I}, 79,76$ and $64 \%$, respectively. Thus there was a small reduction in germination of spores kept on soil for 16 days, but, nevertheless, most spores which did survive for 16 days on soil were viable and germinated. When spores from the same isolates were placed on an agar surface the average germination was $89 \%$. 


\section{DISCUSSION}

Whether streptomycetes exist in soil mainly as spores or mycelia is still debatable. The evidence presented in this paper strongly supports the former view for the following reasons: germinated conidia, when added to unsterilized soil, grew into hyphae, sporulated and then the hyphae disappeared, leaving mainly conidia behind in the soil. Moreover, when conidia of streptomycetes were added to unsterilized soil most failed to germinate. This failure, or inability, to germinate in unsterilized soil does not appear to be an enforced dormancy due to some internal inhibition, for such spores germinated readily on an agar surface, nor is it related to such environmental factors as temperature of the soil or its moisture content, for such spores germinated readily under the same conditions, with the sole difference that the soil had been sterilized previously by irradiation.

Failure to germinate in soil is, however, closely associated with the presence of other soil micro-organisms. Perhaps, as shown by Ko \& Lockwood (I967), for many fungal spores in soil, there is a deficiency of the nutrients required for germination of streptomycete spores, imposed by microbial activity in soil. If so, this would explain why streptomycete spores germinated readily in sterile soil. When soil is sterilized by irradiation sufficient nutrients leak from the killed microbial cells to raise the level of exogenous nutrients sufficiently to promote germination of any streptomycete spores added to this soil. Presumably, also, in unsterilized soil the existence of available exogenous nutrients, such as from decomposing plant or animal residues, would also promote germination of streptomycete spores in the vicinity of the residues.

Within the soil there was a continual decline in the size of the original spore population, for streptomycete spores are not especially resistant to destruction in soil. Therefore, if streptomycetes are to survive in soil, there must be replenishment of spores, and this does occur. A few spores within the population do germinate spontaneously, grow into hyphae and then sporulate, but these alone are insufficient to counteract the higher mortality rate.

The main means for the survival of the species appears to be the partial resistance of spores coupled with intermittent replenishment of the original spore population by mass germination, which is probably induced by the arrival of a suitable organic substrate. The spores germinate and colonize the new substrate with vegetative hyphae. Eventually, profuse sporulation occurs and then the hyphae disappear, perhaps induced to do so through depletion of available nutrients, accumulation of metabolic wasteproducts or even increased competition from other micro-organisms. Whatever the inducement, the hyphae disappear either through lysis or through fragmentation into arthrospores. Left behind is a high density of spores, markers of a once flourishing growth of vegetative hyphae. Such mass germination may endanger the survival of the population if the spores germinate in an environment inadequate to sustain vegetative growth. This seems unlikely with streptomycetes, for a sporophore can be formed almost directly from a germtube and frequently before the hypha is lysed or disappears.

Thus it appears that streptomycetes exist in soil mainly as spores. Mycelium also exists, for it is an essential link between one spore generation and the next. But in general mycelium is restricted to those micro-sites in soil where there is available organic matter adequate to promote spore germination and sustain vegetative growth. Also, perhaps, at other micro-sites such as the surface of soil crumbs exposed to the 
atmosphere there is sufficient reduction in competition to permit vegetative growth. For the rest of the soil, away from decomposing plant or animal residues, streptomycetes exist mainly as spores.

I would like to thank $\mathrm{Mr} \mathrm{N}$. Bumbieris for his technical help.

\section{REFERENCES}

AlEXANDER, M. (1961). Introduction to Soil Microbiology. London: John Wiley and Sons.

BUMBiERIS, M. \& LlOYD, A. B. (1967). Influence of soil fertility and moisture on lysis of fungal hyphae. Aust. J. biol. Sci. 20, I03.

Ko, W. H. \& Lockwood, J. L. (1967). Soil fungistasis: relation to fungal spore nutrition. Phytopatho$\log y \mathbf{5 7}, 894$.

LingaPPA, B. T. \& Lockwood, J. L. (1963). Direct assay of soils for fungistasis. Phytopathology 53, 529.

LiNGAPPA, Y. \& Lockwood, J. L. (1962). Chitin media for selective isolation and culture of actinomycetes. Phytopathology 52, 317 .

LloYd, A. B., Noveroske, R. L. \& Lockwood, J. L. (1965). Lysis of fungal mycelium by Streptomyces spp. and their chitinase systems. Phytopathology 55, 871.

Lutman, B. F., Livingston, R. J. \& SchmidT, A. M. (1936). Soil actinomyces and potato scab. Bull. Vt agric. Exp. Stn, no. 4 or

PfenNG, N. (1958). Beobachtugen des Wachstumsverhaltens von Streptomyceten auf Rossi-Cholod ney-Aufwuchsplatten im Boden. Arch. Mikrobiol. 3I, 206.

PIPER, C. S. (1938). The red-brown earths of South Australia. Trans. R. Soc. S. Aust. 62, 53.

Pridham, T. G. \& GotTlieb, D. (1948). The utilization of carbon compounds by some Actinomycetales as an aid for species determination. J. Bact. 56, 107.

Pridham, T. G., Hesseltine, C. W. \& Benedict, R. G. (1958). A guide for the classification of streptomycetes according to selected groups. Placement of strains in morphological sections. Appl. Microbiol. 6, 52.

SKINNER, F. A. (195I). A method for distinguishing between viable spores and mycelial fragments of actinomycetes in soils. J. gen. Microbiol. 5, 159.

Subrahmanyan, V. (1929). Studies on soil actinomyces. II. Their mode of occurrence in the soil. J. Indian Inst. Sci. 12 (A), 57.

Waksman, S. A. (1959). The Actinomycetes. I. Nature, Occurrence, and Activities. Baltimore: The Williams and Wilkins Co.

\section{EXPLANATION OF PLATE}

(All figures approximately $\times \mathrm{I} 600$ )

Fig. I. Germinated conidia of a Streptomyces sp. recovered immediately after deposition on soil.

Fig. 2. Spiral sporophores of a Streptomyces sp. formed in garden soil 2 to 3 days after addition of germinated conidia to soil.

Fig. 3. Scattered conidia and conidial chains of a Streptomyces sp. formed in garden soil 3 to 4 days after addition of germinated conidia to soil.

Fig. 4. Streptomycete hyphae growing on sterilized garden soil 2 days after addition of germinated conidia to soil.

Fig. 5. Several germtubes growing from a clump of streptomycete conidia I day after addition of conidia to soil. 

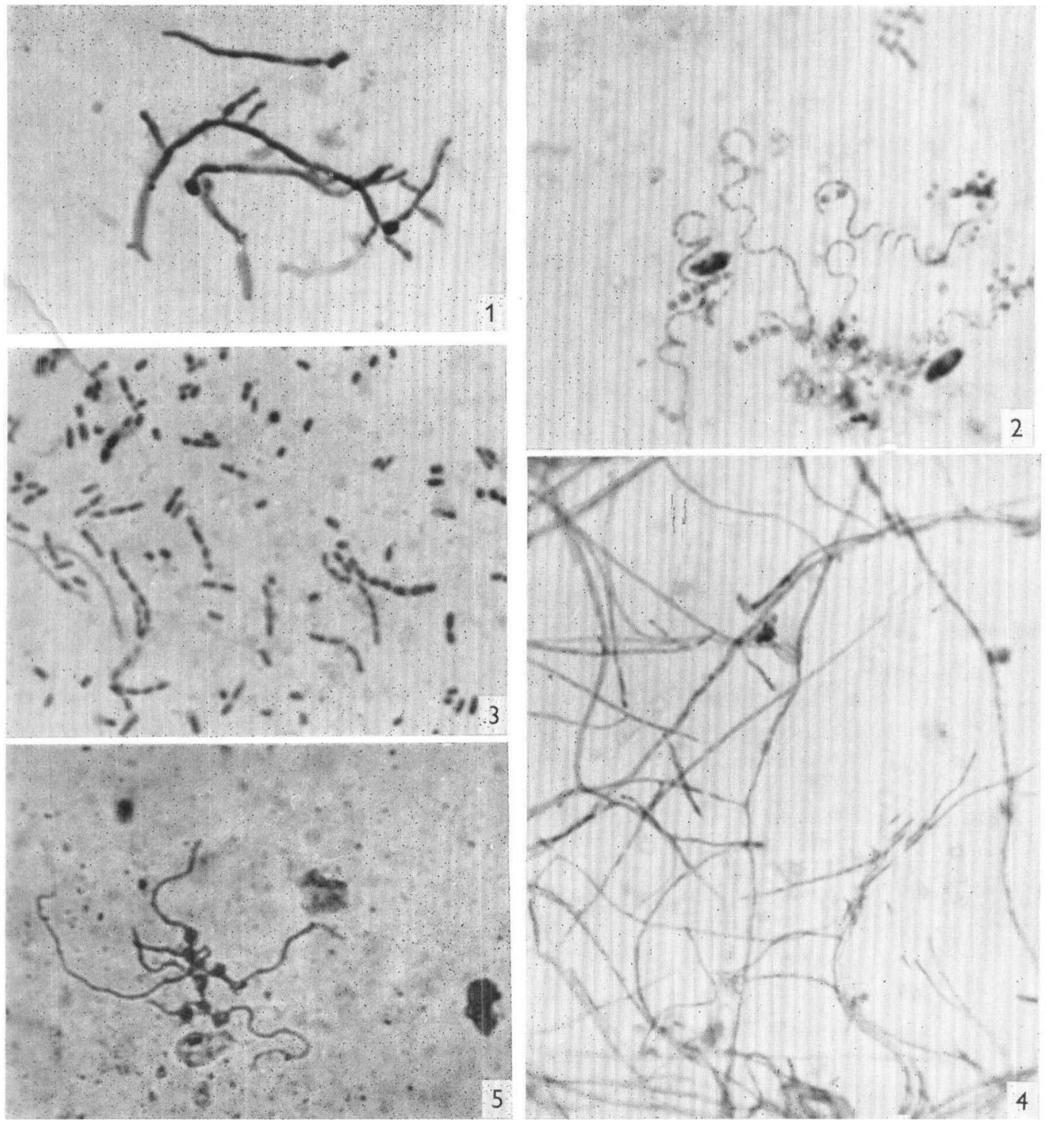